\title{
Research on Thermal Discharge Pollution of Xiangshan Power Plant based on Remote Sensing
}

\author{
Yuan Lin ${ }^{1, a}$, Zhongyang Guo ${ }^{1, b}$, Pengpeng Kan ${ }^{1, c}$, Shufeng Ye $\mathrm{e}^{2, \mathrm{~d}}$ \\ ${ }^{1}$ Key Laboratory of Geographic Information Science, Ministry of Education, East China Normal \\ University, Shanghai 200062, China \\ ${ }^{2}$ East China Sea Environmental Monitoring Center, State Oceanic Administration People's Republic \\ of China, Shanghai 200137, China \\ alinyuanxm@163.com, byguo@geo.ecnu.edu.cn, ${ }^{\mathrm{b}}$ icesnow611@163.com, dysf6@vip.sina.com
}

Keywords: sea surface temperature, thermal discharge, retrieval, remote sensing

\begin{abstract}
Thermal power technology has brought great convenience for human electricity energy demand, but thermal discharge from thermal power plants has caused great harm to the coastal environment. Therefore, it's important to strengthen the monitoring of thermal pollution from power plants for guarantee the normal operation of coastal environment and ecological system. Thermal infrared remote sensing technology provides a new measure for monitoring the thermal discharge. In this paper, we use mono-window algorithm and Landsat thermal infrared data to retrieved the sea surface temperature around Xiangshan Power Plants, and achieved the result of $1 \sim 5.4^{\circ} \mathrm{C}$ temperature rise in $106.52 \mathrm{~km}^{2}$ in Xiangshan Harbor, revealed the spatial distribution regularities of thermal discharge and discussed the influence of thermal discharge on costal environment.
\end{abstract}

\section{Introduction}

With the rapid development of industry, the demand for energy increase, the construction of power plants increase, the installed capacity of power plants expand, and also the demand for condensate increase. For economic and security considerations, China's thermal power plants are built in coastal area mostly. And most of plants use once-through cooling water system which is condense the plants by extract natural water from the lake or ocean, and then discharge the heated water to receiving water directly, the water heated by high temperature in power plants named Thermal Discharge. The temperature of receiving water would raise $6-14 \mathrm{~K}$ after thermal discharge into receiving water, and it would affect the water ecological environment directly or indirectly, known as Thermal Effect ${ }^{[1]}$. While thermal discharge produces negative effects to receiving water ecological environment, it also harms to aquatic organism, this situation is called Thermal Pollution. The sea surface temperature is an important physical quantity reflected the cool or warm of seawater, it depends on solar radiation, sea surface radiation, evaporation, currents and sea water vertical movement and other elements. While the Sea Surface Temperature (SST) refers to the temperature of sea in surface, generally refers to the average temperature of $0.5 \mathrm{~m}$ depth in sea surface. It have important applications in the atmosphere energy and material exchange, weather forecasts, global ocean circulation, climate change.

With the development of Remote Sensing (RS) technology, the thermal infrared RS not only provides favorable conditions for obtain the information about the earth's surface temperature, but also provides a new convenient method for the monitoring of thermal discharge temperature of coastal thermal power plants. Although airborne thermal infrared RS has high spatial resolution and temperature resolution, it has high requirement for airborne platform, and it has economic constraints, susceptible to weather conditions, difficult to acquisition coherent data, cannot form time series data. In contrast, use satellite thermal infrared RS to monitor thermal discharge from thermal power plant can not only reduce monitoring costs, improve monitoring efficiency, but also reflect the spatial diffusion and spatial-temporal changes of thermal discharge on a large scale, has highly practicality. 
Since launched the TIROS-II in early 1960s, scholars had retrieve land surface temperature by using satellite RS data. With the deepening of RS applications, under the premise of known surface emissivity, the use of various approximations and assumptions on the atmospheric radiative transfer equation, have proposed a variety of surface temperature inversion algorithms, such as singlechannel algorithm, sub-window algorithm, single-channel multi-angle algorithm, multi-channel multi-angle algorithm. Trisakti $\mathrm{B}^{[2]}$ developed a new sea surface temperature algorithm for Landsat-7 ETM in comparing with SST of NOAA-12 AVHRR. Digital numbers of Landsat data were converted to effective temperatures based on radiance value, and then the temperatures were compared to SST generated from NOAA data by using field data calibrated algorithm. The results showed that effective SST generated from Landsat data has polynomial correlation with NOAA's SST data, where the accuracy of Landsat B62 is better than B61 on detecting SST. Yu Jie ${ }^{[3]}$ calculated the sea surface temperature in Daya Bay on Landsat TM6 data by using QinZhihao's mono-window algorithm, Jimenez-Munoz's single-channel method and Weng's algorithm, found that the distribution characteristics of SST obtained from the three methods are similar to each other, and show an error of $-2.21^{\circ} \mathrm{C}, 0.19^{\circ} \mathrm{C}$ and $-4.68^{\circ} \mathrm{C}$ compared with the measured temperature, with the error of Jimenez-Munoz's single-channel method being the lowest.

In order to reveal the variation of SST around Xiangshan Power Plant after thermal plants build, and to analyze the intensity and range of thermal discharge in Xiangshan Harbor, in this paper, we choose the Qin Zhihao's mono-window algorithm as research method. Based on this, we achieved the SST of Xiangshan Harbor by retrieved the Landsat thermal infrared RS data, and compared the results of SST in different imaging time.

\section{Study Area and Research Method}

Study area. Xiangshan Harbor is located at $29^{\circ} 05^{\prime} \sim 29^{\circ} 46^{\prime} \mathrm{N}, 121^{\circ} 25^{\prime} \sim 120^{\circ} 00^{\prime} \mathrm{E}$, in the southeastern Ningbo city of northern Zhejiang coastal, on the East China sea. It is a narrow semi-closed bay deeper inland from northeast to southwest and covers an area of $563 \mathrm{~km}^{2}$. Determined by its geographical position, Xiangshan has obvious subtropical monsoon climate characteristics, i.e., four distinctive seasons, long frost-free period, mild and humid, abundant rainfall (the average annual precipitation of above 1400 millimeters), adequate illumination (the average annual temperature of $16-17^{\circ} \mathrm{C}$ ). To relieve the stress of electricity shortage in East Zhejiang, China started to construct two large thermal power plants in Xiangshan Harbor in 2003, namely Guohua Ninghai Power Plant (GNPP) (located at 29 $30^{\prime} 17.94 " \mathrm{~N}, 121^{\circ} 40^{\prime} 2.14^{\prime \prime} \mathrm{E}$ ) and Datang Wushashan Power Plant (DWPP) (located at $29^{\circ} 29^{\prime} 6.39^{\prime \prime} \mathrm{N}, 121^{\circ} 30^{\prime} 48.37^{\prime \prime} \mathrm{E}$ ), they are completed and put into power generation officially by the end of 2006 , the total installed capacity have achieved 4.8 million $\mathrm{kW}$. Xiangshan Harbor is a deeper inland semi-closed bay, its hydrodynamic condition is weak, its ecological environment is very fragile, and there is a potential impact on the waters ecological environment and natural resources while the power plant discharge the warm water into Xiangshan Harbor in long term.

Data sources and preprocessing. We retrieved sea surface temperature around power plant by using Landsat TM thermal infrared RS imagery, and discussed the influence of thermal discharge in environment. The satellite Landsat was launched by NASA, US, it has been launched 7 satellites since the first satellite launched in 1972. And because of the failure of launch Landsat 6 , the faulting of Landsat 7 since 2005, there is only Landsat 5 operation in orbit normal since 2005, until it was retired in 2011. GNPP begins its first generating in 2005, and DWPP begins its generating in 2006, so we choose retrieval imagery from three different imaging time, such as Nov. 8 of 2005 , Oct. 27 of 2008 and Nov. 10 of 2010.

Before using these RS images, some pre-processing steps are taken to correct the radiometric and geometrical distortions of images. Firstly, radiation corrections were performed to reduce the influence of the atmosphere scattering. Then the images are geometrically rectified to the WGS (World Geographic System) with the RMSE (Root Mean Square Error) less than half a pixel, i.e. $15 \mathrm{~m}$. Then the images are cut into Xiangshan Harbor area. 
Research methods. According to Qin's mono-window algorithm ${ }^{[4]}$, the TM Remote Sensing sensor receives the thermal radiation of the surface features, and records the radiation intensity with gray value in RS images. Therefore, the thermal radiation intensity is prior calculated in order to obtain the temperature information. For TM data, the relationship of received radiation intensity $\left(\mathbf{L}_{\lambda}\right)$ and the image gray value $(\mathrm{DN})$ is:

$$
\mathrm{L}_{\lambda}=0.1238+0.005632156 \mathrm{DN}
$$

According to the thermal radiation intensity received by sensor, the pixel brightness temperature of Band $6\left(\mathrm{~T}_{6}\right)$ is calculated by using:

$$
\mathrm{T}_{6}=\mathrm{K}_{2} / \ln \left(1+\mathrm{K}_{1} / \mathrm{L}_{\lambda}\right)
$$

Where $\mathrm{K}_{1}$ and $\mathrm{K}_{2}$ are constant, $\mathrm{K}_{1}=60.776 \mathrm{~m} \cdot \mathrm{W} \cdot \mathrm{cm}^{-2} \cdot \mathrm{sr}^{-1} \cdot \mathrm{m}^{-1}, \mathrm{~K}_{2}=1260.56 \mathrm{~K}$

The vegetation coverage rate $\left(\mathrm{p}_{\mathrm{v}}\right)$ is calculated by Normalized Difference Vegetation Index (NDVI). NDVI is calculable by third and fourth band of TM image, using:

$$
\mathrm{NDVI}=(\mathrm{B} 4-\mathrm{B} 3) /(\mathrm{B} 4+\mathrm{B} 3)
$$

Where B3 and B4 is Band 3 and Band 4 of TM image.

According to NDVI, the vegetation coverage rate $\left(\mathrm{p}_{\mathrm{v}}\right)$ can be identified by using:

$$
\begin{aligned}
& p_{v}=1, \text { Complete Vegetation Cover, NDVI }>0.7 \\
& p_{v}=0, \text { Zero Vegetation Cover, NDVI }<0.05 \\
& p_{\mathrm{v}}=(\text { NDVI }-0.05) / 0.65, \text { Others. }
\end{aligned}
$$

The earth's surface can be divided into three categories roughly: water, natural surface and urban surface. Natural surface is including bare soil surfaces and vegetation surfaces. Urban surface is including buildings surfaces and vegetation surfaces. The surface emissivity of the various types of surface features is different, so we need to calculate the surface emissivity respectively. Therefore, the first step is classifying the TM image, which the image will be divided into three types of surface features, and then calculated the types of surface emissivity $(\varepsilon)$ respectively.

Water surface emissivity: $\varepsilon_{1}=\varepsilon_{\mathrm{w}}=0.995$,

Nature surface emissivity: $\varepsilon_{2}=\mathrm{p}_{\mathrm{v}} \mathrm{R}_{\mathrm{v}} \varepsilon_{\mathrm{v}}+\left(1-\mathrm{p}_{\mathrm{v}}\right) \mathrm{R}_{\mathrm{s}} \varepsilon_{\mathrm{s}}+\mathrm{d} \varepsilon$

Town surface emissivity: $\varepsilon_{3}=\mathrm{p}_{\mathrm{v}} \mathrm{R}_{\mathrm{v}} \varepsilon_{\mathrm{v}}+\left(1-\mathrm{p}_{\mathrm{v}}\right) \mathrm{R}_{\mathrm{m}} \varepsilon_{\mathrm{m}}+\mathrm{d} \varepsilon$,

Where, $\mathrm{R}_{\mathrm{v}}=0.9332+0.0585 \mathrm{p}_{\mathrm{v}}$

Where, Water Surface emissivity: $\varepsilon_{\mathrm{w}}=0.995$

$$
\begin{aligned}
& \mathrm{R}_{\mathrm{s}}=0.9902+0.1068 \mathrm{p}_{\mathrm{v}} \\
& \mathrm{R}_{\mathrm{m}}=0.9886+0.1287 \mathrm{p}_{\mathrm{v}}
\end{aligned}
$$

Vegetation Surface emissivity: $\varepsilon_{\mathrm{v}}=0.986$

Bare Surface emissivity: $\varepsilon_{\mathrm{s}}=0.97215$

Building Surface emissivity: $\varepsilon_{\mathrm{m}}=0.970$

The average atmospheric temperature $\left(\mathrm{T}_{\mathrm{a}}\right)$ is related to the earth's surface temperature $\left(\mathrm{T}_{0}\right)$ when the image was imaging, using:

Mid-latitude mean atmospheric of summer: $\mathrm{T}_{\mathrm{a}}=16.0110+0.92621 \mathrm{~T}_{0}$

Mid-latitude mean atmospheric of winter: $\mathrm{T}_{\mathrm{a}}=19.2704+0.91118 \mathrm{~T}_{0}$

Atmospheric transmissivity $(\tau)$ is estimated by water content in atmosphere $(w)$. As Xiangshan is located in coastal zone, has high water content in atmosphere, it can be estimate as: $\mathrm{w}=2.5 \mathrm{~g} /$ $\mathrm{cm}^{2}$. So, while water content $(\mathrm{w})$ in atmosphere is ranged among $1.6-3.0 \mathrm{~g} / \mathrm{cm}^{2}$, the atmospheric transmissivity $(\tau)$ is

High temperature: $\tau=1.031412-0.11536 \mathrm{w}$;

Low temperature: $\tau=1.053710-0.14142 \mathrm{w}$.

Thus the surface temperature is available when the images imaging:

$$
\mathrm{T}_{\mathrm{s}}=\left\{67.3554(\mathrm{C}+\mathrm{D}-1)+[0.4414(\mathrm{C}+\mathrm{D})+0.4586] \mathrm{T}_{6}-\mathrm{DT}_{\mathrm{a}}\right\} / \mathrm{C}
$$

Where, $C=\varepsilon \tau, D=(1-\varepsilon)[1+(1-\varepsilon) \tau]$,

Where, $\tau$ is atmospheric transmittance, $\varepsilon$ is surface emissivity. 


\section{Results analyze and Discussion}

Results of SST. According to the calculate method of SST, we can achieve the result of SST in three different imaging time about Xiangshan Power Plant (Fig.1).

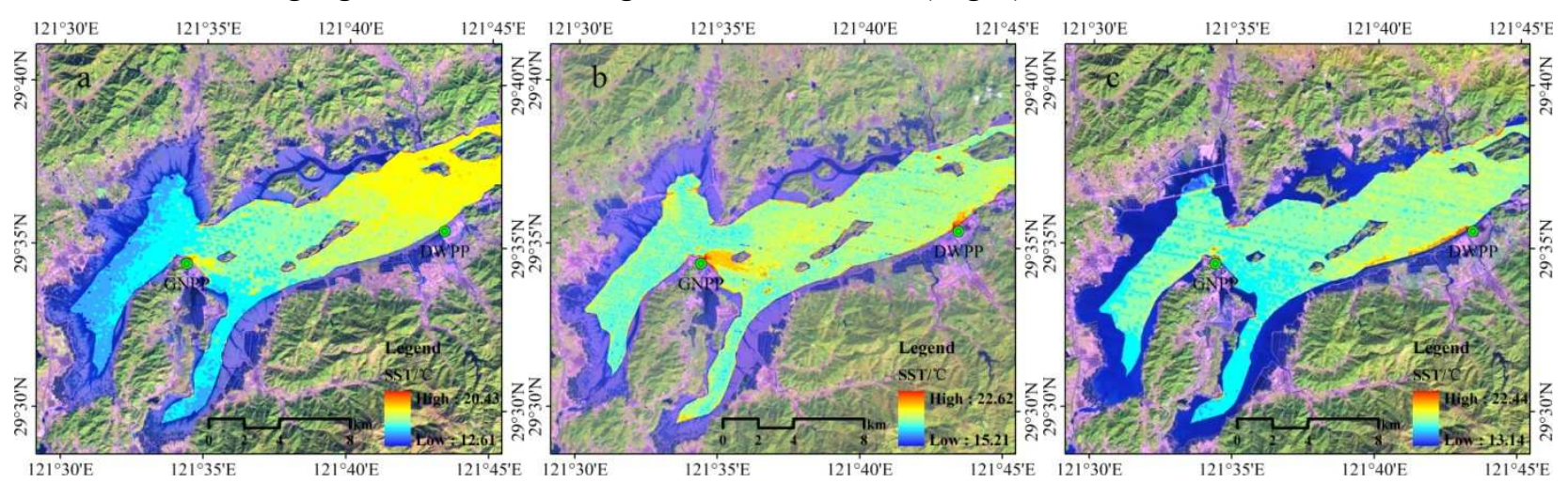

Fig.1 The Sea Surface Temperature in Xiangshan Harbor. (a)Nov.8, 2005; (b) Oct.27, 2008;(c) Nov.10, 2010

In Fig.1(a), the SST of Nov. 8 of 2005 was ranged among $12.6 \sim 20.4^{\circ} \mathrm{C}$, it is obviously that the SST of GNPP was higher than surrounding waters of $1 \sim 4^{\circ} \mathrm{C}$, while the warming of water is hardly can be seen around DWPP because of it was not operation. In Fig.1(b), the SST of Oct. 27 of 2008 was ranged among $15.2 \sim 22.6^{\circ} \mathrm{C}$, it is obviously that the SST of GNPP and DWPP were both higher than surrounding waters of $1 \sim 5^{\circ} \mathrm{C}$. In Fig.1(c), the SST of Nov. 10 of 2010 was ranged among 13.1 22.4 ${ }^{\circ} \mathrm{C}$, it is $1 \sim 5^{\circ} \mathrm{C}$ of water rising can be seen around the GNPP and DWPP.

Analysis of the variation in SST. Response to the tidal wave, the influence range of thermal discharge is different. According to the figures, the image of 2005 and 2008 were imaged at low tide, a large amount of water poured out the mouth of bay. Under the drive of water, the thermal discharge of GNPP was present as radiate current outwards the bay mouth, and the thermal discharge of DWPP was present as alongshore current towards the bay mouth, the range of diffusion is obvious but not wide. The image of 2010 was imaged at high tide; it faced an influx of water into the bay, thermal discharge driven by the tide toward the bottom of bay, and close to the shore impacted by costal terrace (Fig.2). The thermal discharge from GNPP were gathered at the cape because of the resistance of cape in Fig.2(a), and the effect of thermal discharge were weak behind the cape. In Fig.2(b), there were no resistance terrain, the thermal discharge of DWPP were spread along the shore.


Fig.2 The Influence Range of Thermal Discharge. (a) GNPP; (b) DWPP.

The power plant was initial trial run in November of 2005, and was normal operation in 2008. Because the data of image was imaged in similar period and the impact of tidal fluctuation, so we choose the image of 2005 and 2008 that were both imaged at low tide to compare and analyze the variation of SST. 
Subtract two images, we can obtain the increasing zone and decreasing zone and intensify of temperature variation between the early and lately stage of plant operation (Fig.3). The increasing zone was located on the western and bottom of Xiangshan Harbor, it is because of that region is coastal wetland which has silting-up year by year, and impacted by the silt content and tide, result to an abnormal short-term increasing while the satellite crossing the region. Meanwhile, the temperature was relatively low in the eastern and mouth of Xiangshan Harbor, it's not only because of the injection of river from land, but also of the water is relatively deep, and is less susceptible to the effects of silt and tidal. However, due to the thermal power plants, the middle of harbor between them had significant increasing zone with the highest temperature rise of $5.4^{\circ} \mathrm{C}$.

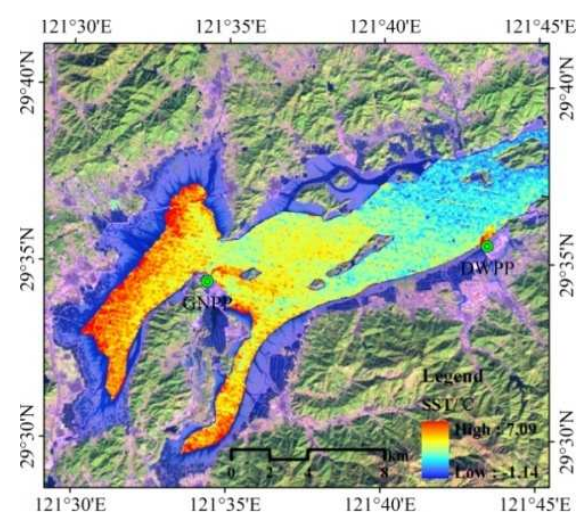

Table 1. The intensive of increasing temperature and area statistics

\begin{tabular}{ccc}
\hline Increasing intensive $\left({ }^{\circ} \mathrm{C}\right)$ & Increasing area $\left(\mathrm{m}^{2}\right)$ & Rate $(\%)$ \\
\hline $0 \sim 1$ & 22681207.69 & 21.29 \\
$1 \sim 2$ & 40909975.89 & 38.41 \\
$2 \sim 3$ & 20637166.32 & 19.37 \\
$3 \sim 4$ & 19131158.42 & 17.96 \\
$4 \sim 5$ & 2986510.83 & 2.80 \\
$5 \sim 6$ & 171247.68 & 0.16 \\
\hline
\end{tabular}

Fig. 3 The variation of SST between 2005 and

2008

According to Fig.3 and Table 1, the range of temperature rise around two power plants were $106.52 \mathrm{~km}^{2}$ totally, the region of temperature rise were spread from power plant outfall to bay mouth, and the intense of temperature rise decrease. The area of rise $0 \sim 1{ }^{\circ} \mathrm{C}$ were $22.68 \mathrm{~km}^{2}$, accounting for $21.3 \%$ of whole temperature rise region, mainly in the eastern and outer of harbor away from the DWPP, reflected as flowing expanded along the coastline towards harbor mouth. The area of rise $1 \sim 2^{\circ} \mathrm{C}$ were $40.91 \mathrm{~km}^{2}$, accounting for $38.4 \%$ of whole increasing region, mainly between in the sea of two power plants, east from the GNPP with the distance of $5 \sim 10 \mathrm{~km}$, are the mainly temperature rise range with relatively continuous distribution in region. The region of rise more than $2{ }^{\circ} \mathrm{C}$ were accounting for $40.4 \%$ of all temperature rise region, which mainly distributed in the distance of $3 \mathrm{~km}$ away from the GNPP. The rise more than $5^{\circ} \mathrm{C}$ were distributed in the distance of $500 \mathrm{~m}$ away from the outfall of GNPP, only had the area of $0.17 \mathrm{~km}^{2}$, accounting for $0.16 \%$ of all region. While the region of rise $6 \sim 7^{\circ} \mathrm{C}$ were distributed in wetland because of an abnormal short-term increasing on the bottom of harbor, which is not included in this study.

Impacted on coastal environment of thermal discharge. 1) Water temperature is an important factor in water quality and ecological environment, it is an important environmental condition in aquatic ecosystems, and it affects almost all properties of water, such as physical properties, chemical properties and biochemical properties. Thermal discharge from the coastal power plant will raise the temperature of water in short time, will make the water temperature higher than natural water in a certain area and depth, will change the physical and chemical properties of water, especially in water temperature and dissolved oxygen ${ }^{11]}$. Also, thermal discharge will mix the water, reduce the transparency of water, increase the ammonia content in water, strengthen the salinity in water, increase the total phosphorus and nitrogen content in water, and accelerate the process of eutrophication of water.

2) There were both positive and negative for aquatic organisms after thermal discharge warming the water. One hand, in the spring, autumn and winter, especially in the temperate and frigid regions, there is positive impacts for aquatic organisms with thermal discharge warming water. In temperate regions, the warming of thermal discharge cannot do obvious harm to wetland vegetation, plankton, benthos, fish, etc., but will increase the abundance of marine creature and biodiversity 
index in low water temperature season. On the other hand, thermal discharge from power plants has a huge impact on the marine environment and marine creature. They can change the dissolved oxygen in water and the physical and chemical properties of water. And the water temperature will raise more than $5^{\circ} \mathrm{C}$ after cooling water through $\mathrm{DC}$-cooling system, the high temperature and heating rate around the outfall have a negative influence on growth and development, metabolism, and germ cell maturation and life cycle of biological individual ${ }^{[5]}$.

3) Benthos habitats on the bottom surface of underwater in long term, they are relatively fixed and weak migration. So they are negative impacted by thermal discharge unavoidably, the influence reflected as the disappearance of benthos ${ }^{[6]}$.

4) The rapid changes of temperature have different effects on reproduction, embryonic development and survival of fish. After thermal discharge into receiving water, it will change the normal distribution of fish and other aquatic organisms in water, change the community structure of creature, even will cause the abnormal development of fish, lead to serious impact of some migratory fish ${ }^{[7]}$.

5) The large amounts of thermal discharge from power plant will promote the proliferation of aquatic organisms in waters, resulting in the reduction of dissolved oxygen and purification capacity of water, extending the growing time of algae. And the nitrogen and phosphorus in sediment will be released, the content of nitrogen and phosphorus in water will reach the needs of eutrophication, result to accelerated the rate of eutrophication, which form a vicious circle. Especially in the harbor region, the thermal discharge were diffused slow, the proceed of water exchange cycle is slow, more possibly to cause water eutrophication ${ }^{[8,9]}$.

\section{Conclusions}

Through the research of thermal discharge pollution of Xiangshan Power Plants based on remote sensing technology, we found that, thermal infrared RS technology can provide a convenient method for the study of SST with the improvement of RS technology and research methods. The warming influence of thermal discharge on Xiangshan Harbor is ranged among $1 \sim 5.4^{\circ} \mathrm{C}$ in $106.52 \mathrm{~km}^{2}$, with the highest temperature rise of $5.4^{\circ} \mathrm{C}$. From the scale aspect, the thermal discharge influence the most regions of middle Xiangshan Harbor, the temperature of rise of $0 \sim 2{ }^{\circ} \mathrm{C}$ accounted for $60 \%$ of whole rise region, and the temperature of rise of more than $2{ }^{\circ} \mathrm{C}$ accounted for $40 \%$ of all. The rise range of thermal discharge gradually weakened from the outfall of power plant to outer. And due to different tidal fluctuations, the influence ranged different. While there is a high tide, water poured into harbor, the warming current spread from east to west towards the bay bottom; while there is a low tide, water poured out from harbor, the warming current spread from west to east towards the bay mouth. In addition, thermal discharge have great impact on the coastal environment, such as rise water temperature, have both beneficial and adverse effects to aquatic organisms, have disadvantage effects to benthos, may lead abnormal changes on fish, and may cause the water eutrophication.

\section{Acknowledgment}

This study is supported by the Public Science and Technology Research Funds Projects of Ocean (Grant No. 200905010). 


\section{References}

[1] Jin Lan. Introduction of Water Thermal Impact.,Beijing, 1993.

[2] Trisakti B, Sulma S, Budhiman S. Study of Sea Surface Temperature (SST) using Landsat-7/ETM (In Comparison with Sea Surface Temperature of NOAA- 12 AVHRR). Proceedings The Thirteenth Workshop of OMISAR (WOM-13) on Validation and Application of Satellite Data for Marine Resources Conservation. Bali.(2004).

[3] Yu Jie, Li Yongzhen, etc. SST Retrieving of Daya Bay from LANDSAT TM6. Remote sensing for land \& resource, (2009). 81(3): 24-29.

[4] Qin Zhihao, Zhang Minghua, ArnonKarnieli,etc. Mono-window Algorithm for Retrieving Land Surface Temperature from Landsat TM6 Data. ACTA Geographic Sinica,(2001), 56(4): 456-466.

[5] Jiang Zhibing, Zengjiangning, Chen Quanzhen, ect. Effect of heating rate on the upper incipient lethal temperature for copepods. Journal of Tropical Oceangraphy,(2010). 29(3): 87-92.

[6] Yu Fan, Zhang Yongxing, Cao Ying. The Influence on of NPP Warm Drainage on the Marine Ecosystem in the context of Global Warming. Transaction audit of Oceanology and Limnology, (2010). 2: 155-161.

[7] Yu Fan, Zhang Yongxing.The Review on the Efects of Thermal Emuent from Nuclear Plantson the M arine Ecosystem. Radiation Protection Transmission, (2008). 163:1-7.

[8] XuLianfeng. Discussion the impact of coastal thermal discharge on water eutrophication. Environmental Pollution \& Control, (1990). 12(6): 6-8.

[9] Liu Yu, Wang Dianliang, Water eutrophication and thermal discharge from power plant, Electric environmental protection, (1991).7(3): 23-27. 